\title{
SURGICAL OUTCOME OF PERCUTANEOUS ENDOSCOPIC INTERLAMINAR LUMBAR DISCECTOMY TECHNIQUE
}

\author{
By \\ Osama El-Ghannam*, Mamoon Abo-Shosha*, Hatem Saad Al-Kholy*, \\ Hussein Montaser** and Ahmed Fathi El-Sayed*
}

Departments of Neurosurgery*and Radiology**, Al-Azhar Faculty of Medicine

E-mail: afathyneuro@gmail.com

\begin{abstract}
Background: Minimally invasive lumbar surgeries are becoming more popular and a routine around the world. Although good surgical outcomes have been reported for the endoscopic approach to treat lumbar disc herniation $(\mathrm{LDH})$, the procedure still appears to be relatively difficult so operative failures and complications may be occurred.
\end{abstract}

Objective: To assess the outcome of lumbar spinal endoscopic discectomy by Destandaeu technique as minimally invasive approach in Al Azhar experience.

Patients and Method: Thirty five consecutive patients proved to have lumber disc prolapse, were treated with percutaneous endoscopic lumbar discectomy through interlaminar approach discectomy by Destandau's technique using Endospine Karl Storz system between September 2017 and October 2019 at the Neurosurgery Department, Al-Azhar University Hospitals. All patients included in this study have lumbar disc prolapse fulfilled the following criteria: Unilateral Radicular pain correlated with MRI finding, failure of conservative measures for at least 6 weeks, single level disc prolapse, and disc prolapse was central or paracentral. Follow up for 6 months postoperative and Clinical outcomes were assessed by using Visual Analogue Scale (VAS) score (for Mean pre- and postoperative pain score measurement) and Oswestry Disability Index (ODI), Patients Satisfaction measured by Modified Macnab Criteria at 6 months postoperative, Time of return to work, Recurrence or persistence of symptoms which need revision open surgery.

Results: The mean age was 37.5 years, the mean operative time was 90 minutes, and the mean length of follow-up was 5 months. The mean hospital stay for endoscopic discectomy was 36 hours. There was a significant reduction in the severity of back pain and lower limb symptoms measured by (VAS) (ODI) in $87 \%$ (30 patients) at 6 months. The recurrence rate was $8.5 \%$ (3 patients) and persistent symptoms without improvement occurred in $5.7 \%$ (2 patients) who subsequently underwent revision surgery. Most Patients returned to their previous occupation after surgery at a mean time of 35 days.

Conclusion: Endoscopic discectomy by Destandau's technique for lumbar disc prolapse in properly selected patients was safe and minimally invasive technique.

Key words: Endoscopic spine, endoscopic technique, interlaminar approach, lumbar discectomy, minimally invasive.

\section{INTRODUCTION}

Lumbar degenerative disc disease is a condition which causes anatomical and morphological changes leading to clinical complaints. Lumbar disc herniation $(\mathrm{LDH})$ is a common neurosurgical disease which causes economic and medical burdens to families, society and country. Lumbar disc degenerative disease is the 
most common cause of low back pain all over the world (Weiler et al., 2011). In the industrialized areas of the world, low back pain is extremely common. It is the most common cause of disability above the age of 45 years, and second most common reason for primary care physician visit (Lehtola et al., 2012). People throughout the world consume more than 100 billion US dollars/year for the treatment of low back pain. Despite the high prevalence of low back pain in both developing and developed countries, it is still enigmatic in terms of cause, diagnosis and treatment (Weiler et al., 2011).

Lumbar degeneration can occur at any level but mainly it occurs on L3-L4, L4L5 and L5-S1 vertebrae (Bakhsh, 2010 and David et al., 2010). Lumbar disc degenerative disease may present as disc herniation, lumbar stenosis, facet joint arthropathy or their combination. Herniation occurs when nuclear materials protrude or emerge from inside the disc to perineural structures through radial tears of the annulus fibrosus (Choi, 2009). The most common symptom associated with lumbar disc prolapse is low back pain, and it is due to the presence of neural tissue around the intervertebral disc. The main symptom of disc herniation after low back pain is sciatica. Features suggestive of sciatica are unilateral or bilateral lower limb pain radiating to the feet and toes, presence of numbness in dermatomes distribution and positive straight leg raising test. Sciatic pain aggravates on some situation as standing, walking, straining, bending and coughing (Bakhsh, 2010). Since its introduction in early 20th century, endoscopy has advanced rapidly, and becoming the standard approach in various clinical diagnostic and therapeutic procedures. Endoscopy has become increasingly popular with physicians because of its ability to minimize traumatization and adverse procedural consequences. Currently, the treatment options for LDH include conventional discectomy (CD) and percutaneous endoscopic lumbar discectomy (PELD). Because of its high success rate of approximately $90 \%$ and good result, CD is considered the standard surgical method in the management of $\mathrm{LDH}$ unresponsive to conservative therapy. However, CD is associated with some complications, including epidural scarring, destabilization of spinal canal structures, and tissue traumatization (Serdar and Sedat, 2016). The technical advancement in endoscopes and instruments has led to the development of multiple approaches including the transforaminal, the extra foraminal and the interlaminar approach. The interlaminar approach is used in lumbar spinal stenosis and disc herniation located mainly inside the spinal canal, which is technically difficult to treat using the transforaminal technique, and especially at L5-S1 due to the large transverse processes, facets, the narrow disk space and the iliac crest (Choi et al., 2013-b). Spine surgeons are familiar with IL-PELD as the anatomic orientations involved are similar to open surgery, although there is a learning curve. The systems for endoscopic interlaminar approach are either a conic "freehand" working channel (the Endospine by J. Destandeau) or a tubular retractor (Metrx system, Medtronics), introduced by Foley and Smith. Despite the remarkable evolution of endoscopic techniques and instrumentation leading to successful outcomes comparable to conventional 
open surgery, surgeons still have some difficulty in PELD (Lee et al., 2009).

\section{PATIENTS AND METHODS}

Thirty five consecutive patients proved to have lumber disc prolapse, were treated with percutaneous endoscopic lumbar discectomy through interlaminar approach discectomy by Destandau's technique using Endospine Karl Storz system between September 2017 and October 2019 at the Neurosurgery Department, AlAzhar University Hospitals. All patients included in this study have lumbar disc prolapse and fulfilled the following criteria: Unilateral Radicular pain correlated with MRI finding, failure of conservative measures for at least 6 weeks, single level disc prolapse. Disc prolapse is central or paracentral. The following patients were excluded from this study: Cases proved to have bilateral radiculopathy, more than one level disc prolapse, calcified discs, spondylosis, spondylolisthesis or previous lumbar spine surgery, and cauda equina syndrome, associated bony stenosis. All patients in this study were subjected to the following: Clinical assessment (history and examination, radiological assessment by MRI lumbosacral spine and plain X-ray lumbosacral spine (A-P and lateral views), surgical treatment by interlaminar PELD by Destandaeu technique. Lengths of hospitalization, postoperative complications were recorded. Follow up for 6 months postoperative and clinical outcomes were assessed by using Visual Analogue Scale (VAS) score (for Mean pre- and postoperative pain score measurement) and Oswestry Disability Index (ODI). Patients Satisfaction was measured by Modified Macnab Criteria at
6 months postoperatively, time of return to work, recurrence or persistence of symptoms which needed revision open surgery were recorded in follow up period. In this study, Destandau endospine system was used. It consisted of endospine tube, trocar, and working insert. The working insert comprised of four ports: One port for 0 degree endoscope, second for suction cannula, third port (biggest) for working instrument, and fourth port for dural and nerve root retractor.

Follow up for 6 months postoperative and clinical outcomes were assessed.

Data were collected, revised, coded and entered to the Statistical Package for Social Science (IBM SPSS) version 21. The distribution of quantitative data was tested by Kolmogorov-Smirnov test of normality. So, the quantitative data were presented as mean, standard deviations and ranges when parametric while nonparametric were presented as median with inter-quartile range (IQR). Also, qualitative variables were presented as number and percentages.

The comparison between groups regarding qualitative data was done by using Chi-square test and/or Fisher exact test when the expected count in any cell found less than 5. The comparison between two independent groups with quantitative data and parametric distribution was done by using Independent t-test while with nonparametric distribution was done by using Mann-Whitney test. The comparison between two paired groups with quantitative data and parametric distribution was done by using Paired ttest. The confidence interval was set to 
95\% and the margin of error accepted was set to $5 \%$. P-value $<0.05$ was considered
Significant.

\section{RESULTS}

The mean age of the patients was 37.5 years (range $20-55$ years). There were $16(45.7 \%)$ female and $19(54.3 \%)$ male. There were $14(40 \%)$ cases RT sciatica, $21(60 \%)$ cases LT sciatica. There were 12
(34.3\%) cases of L5-S1 disc prolapse and 23 (65.7) cases of L4-5 disc prolapse. There were $30(85.7 \%)$ Cases Paracentral disc protrusion and $5(14.3 \%)$ Cases central disc protrusion (Table 1).

Table (1): Demographic Criteria

\begin{tabular}{|c|c|c|}
\hline \multirow{2}{*}{ Age } & Range & Mean \\
\hline & $20-55$ years & 37.5 years \\
\hline \multirow[t]{2}{*}{ Sex } & 19 cases males & 16 female \\
\hline & $54.3 \%$ & $45.7 \%$ \\
\hline \multirow{2}{*}{$\begin{array}{l}\text { Radicular pain } \\
\text { side }\end{array}$} & 14 cases RT sciatica & 21 cases $L T$ sciatica \\
\hline & $40 \%$ & $60 \%$ \\
\hline \multirow[t]{2}{*}{ Disc level } & 12 cases of L5-S1 disc prolapse & $\begin{array}{lllll}23 & \text { cases of } L 4-5 & \text { disc } \\
\text { prolapse } & & & \\
\end{array}$ \\
\hline & $34.3 \%$ & $65.7 \%$ \\
\hline \multirow[t]{2}{*}{$\begin{array}{l}\text { Types of disc } \\
\text { protrusion }\end{array}$} & $\begin{array}{l}30 \text { Cases Paracentral disc } \\
\text { protrusion }\end{array}$ & $\begin{array}{lrll}5 & \text { Cases } & \text { central } & \text { disc } \\
\text { protrusion } & & \end{array}$ \\
\hline & $85.7 \%$ & $14.3 \%$ \\
\hline
\end{tabular}

The mean operative time was $90 \mathrm{~min}$ (60-120 min). The mean average blood loss $50 \mathrm{ml}$ (25-60). The mean length of hospitalization was 36 hours (range 24 to 48 hours). The mean follow-up period was 5 months (range $4-6$ months). All patients who were working preoperatively returned to work. The mean time to return to work was 35 days $(10-60$ days $)$. All returned to their previous occupation. Postoperative improvement of sciatica occurred in 27 patients $(80 \%)$ and 8patients (20\%) not improved. Postoperative complications occurred in 7 patients (17\%); Incidental durotomy occur in 3 cases $(7 \%)$, Nerve injury occur in 3 cases $(7 \%)$ laceration of nerve root occurred in 1 case and neuropraxia in 2 cases, the 2 neuropraxia cases improved by medical treatment in form of neurotonics. Infection occurs in 1 case (3\%) and patient was diabetic and improved by antibiotics. Recurrence of symptoms occurred in 2 cases $(5.5 \%)$ ) 5 cases have been reoperated due to residual disc fragment in 3 cases and recurrent disc in 2 cases, all 5 cases improved after second procedure as regard radicular pain with persistence numbness in two recurrent cases (Table 2). 
SURGICAL OUTCOME OF PERCUTANEOUS ENDOSCOPIC...

Table (2): Results and Outcome

\begin{tabular}{|c|c|c|}
\hline \multirow[t]{2}{*}{ Operative time } & Range & Mean \\
\hline & $60-120 \mathrm{~min}$ & $90 \mathrm{~min}$ \\
\hline \multirow[t]{2}{*}{ Average blood loss } & Range & Mean \\
\hline & $25-60 \mathrm{ml}$ & $50 \mathrm{ml}$ \\
\hline \multirow[t]{2}{*}{ Length of hospital stay } & Range & Mean \\
\hline & 24-48 hrs & 36hrs \\
\hline \multirow[t]{2}{*}{ Follow up period } & range & mean \\
\hline & 4-6 months & 5 months \\
\hline \multirow{2}{*}{$\begin{array}{l}\text { Mean Time To Return To } \\
\text { Work }\end{array}$} & Range & Mean \\
\hline & $10-60$ days & 35 days \\
\hline \multirow[t]{2}{*}{ Pain Scores : } & improved in 27 patients & $\begin{array}{l}\text { not improved } \\
\text { in } 8 \text { patients }\end{array}$ \\
\hline & $77.1 \%$ & $22.9 \%$ \\
\hline \multirow[t]{3}{*}{ complications } & $\begin{array}{l}\text { Incidental durotomy occur } \\
\text { in } 3 \text { cases }\end{array}$ & $8.6 \%$ \\
\hline & $\begin{array}{l}\text { Nerve injury occur in } 3 \\
\text { cases }\end{array}$ & $8.6 \%$ \\
\hline & Infection occur in 1 cases & $2.9 \%$ \\
\hline $\begin{array}{l}\text { Failure with persistent } \\
\text { symptoms }\end{array}$ & 3 case & $8.6 \%$ \\
\hline Recurrence of symptoms & 2 cases & $5.7 \%$ \\
\hline Reoperation rate & 5 cases & $14.3 \%$ \\
\hline
\end{tabular}

\section{DISCUSSION}

Conventional open surgery remains the 'gold standard' for treating herniated intervertebral disc. However the disadvantages of open surgery include extensive retraction and dissection of paraspinal muscles, longer operative time, larger wounds and bone resection (Chan et al., 2009). Percutaneous endoscopic discectomy is a relatively new technique for removing lumbar disc herniation. Endoscopic technique is theoretically less invasive with minimal trauma during approach. This is possible due to continued improvement in illumination and focus with greater circumferential view by applying angled optics. The theoretical advantages of endoscopic discectomy are reduced post-operative pain and small scar due to minimal opening leading to shorter recovery time and hospital stay.

Spine surgeons are familiar with ILPELD as the anatomic orientations involved are similar to open surgery, although there is a learning curve (Wang et al., 2011).

Standard open approach leads to iatrogenic injury of the paraspinal muscle which correlated to decrease strength in the paraspinal muscles as well as the presence of atrophy after extensive muscle retraction. It seems reasonable to consider the microendoscopic technique for interlaminar fenestration as a relatively minimal invasive procedure with concern 
to the paraspinal muscles. Biomechanical studies have investigated the function of the posterior column and its importance in maintaining lumbar spinal stability (Chan et al., 2009).

Lumbar microdiscectomy remained the gold standard for addressing a herniated or sequestrated intervertebral disc; however, a movement toward more minimally invasive approaches that would yield superior outcomes, while minimizing excessive soft and bony tissue removal and minimizing soft tissue trauma, were sought. As such, an evolution in procedures toward smaller incisions, less tissue trauma, and quicker return to daily activities took center stage in spine surgery. The $90 \%$ excellent results in a study are comparable with other surgical procedures for herniated lumbar discs (Kaushal and Sen, 2012).

In this study, the hospital stay was 1 to 2 days, average operative time was 90 minutes and average blood loss was $50 \mathrm{ml}$ (range, 25-60 ml). Complication rate was $17 \%$. Return to work (35 days. In this study current series, there was three case (7\%) incidence of dural injury one of them needs conversion of procedure to open discectomy to repair the dura as tear is large and dura is collapsed that necessitate open procedure for dural repair to prevent CSF leak and infection and preventing early post-operative epidural hematoma, another two cases were very small puncture and the arachenoid layer was intact and thecal sac was not collapsed and managed intraoperatively by putting small piece of gel foam on the puncture site combined with bed rest for 24 hours post-operative and the two patients didn't suffer from CSF leak. some studies reported encouraging outcomes. In series reported by Ahn et al. (2011), a total of nine patients $(1.1 \%)$ experienced symptomatic dural tears. In series reported by Lee et al. (2009) and Xia et al. (2013), there was no case of intraoperative incidental durotomy or cerebrospinal fluid leakage after surgery. In series reported by Hongfei et al. (2018), dural tear occurred in $0.9 \%$. In series reported by Chen et al. (2019), dural tear and cerebrospinal fluid leakage were observed in 3 patients because of adhesions between the calcification of disc and nerve root. However, their symptoms improved, and they were discharged after 1 week of bed rest.

In this study, there were three cases have nerve root injury, laceration in one case and neuropraxia in two cases and in the three cases. The disc was large and the nerve root was severely stretched by the discs which necessitate excessive nerve root traction that cause traction injury and nerve ischemia in two cases and incidental nerve root laceration in one case. In neuropraxia cases, the two patients were presented with post-operative muscle weakness and hyposthia along the distribution of the affected nerve root which improved gradually within three months post-operatively by medications and physiotherapy, but in the patient with nerve root laceration, persistent anesthesia and weakness occurred which continued for more than six month post-operatively during follow up period. In series reported by Hongfei et al. (2018), nerve root injury occurred in $1.2 \%$ of cases. Choi et al. (2013-a) noted that the working sheath might compress the exiting nerve root during the procedure, and thus a prolonged operative time could lead to 
nerve irritation. Furthermore, motor weakness and temporary dysesthesia were reported as common complications in PELD. These complications showed an incidence of 2-6.53\% according to previous studies by Lee et al. (2016).

In this study, the infection occurred in one case (3\%) and the patient was diabetic and improved by antibiotics. In series reported by Cao et al. (2019), no patient noted with postoperative infections after PELD. In series reported by Hongfei et al. (2018), there were no instances of posterior surgical site infection.

In this study, the reoperation was done in 5 cases $(15 \%)$ due to residual disc fragment in 3 cases and recurrent disc in 2 cases. In the first three cases with residual disc fragment, the patients have persistent symptoms after endoscopic procedure without any improvement in 2 cases and partial improvement in one case. All 5 cases improved after second open procedure as regard radicular pain with persistence numbness in two recurrent cases.

Series have reported reoperation rate of 5.5, 5.7, and 3\%, respectively (Kaushal and Sen, 2012). In series reported by Joswig et al. (2016), recurrent lumbar disc herniations occurred in $28 \%$. Recurrence rates after discectomy vary between 5 to $20 \%$ being independent from the technique employed. Success rate for revision operations, on the other hand, is worse than primary operations due to epidural fibrosis scar tissue, stenosis, arachnoiditis, segmental instability and additional traumas to develop during the revision procedure. Epidural fibrosis is the most important risk factor in terms of causing injuries to the dura and neural structures (Ruetten et al., 2009).

Another measure of success is reflected by the patient's ability to return to previous employment. In this study, the patients returned to previous employment on an average 35 days with restriction to avoid heavy manual work for 2 months.

Despite the remarkable evolution of endoscopic techniques and instrumentation leading to successful outcomes comparable to conventional open surgery, surgeons still have some difficulty in PELD. Most concerns are about the incomplete removal of disc fragments, a steep learning curve, recurrence, radiation exposure. The risk of surgical failure may be a major obstacle to performing PELD, PELD technique and experience can affect success of PELD. During the steep learning curve phase, longer operation times are required and the incidence of complication may be higher than those by experienced surgeons (Choi et al., 2015).

One of the driving forces behind the minimal invasive spine surgery is economics, shorter hospital stay, reduced postoperative morbidity, and quicker recovery times. Depth perception in these techniques comes from experience rather than observation. Hence, surgeon keen to learn these techniques must combine these procedures during early phase of learning with standard procedures in clinical practice (Kaushal and Sen, 2012).

\section{CONCLUSION}

Endoscopic discectomy by Destandau's technique for lumbar disc prolapse in properly selected patients was a safe and minimally invasive technique with some 
difficulties such as a steep learning curve and the incomplete removal of disc fragments. Patients were mobilized early and are comfortable after surgery because of reduced pain. The hospital stay was also significantly reduced and they can go back to work early.

\section{REFERENCES}

1. Ahn, Y., Lee, H. Y., Lee, S. H. and Lee, J. H. (2011): Dural tears in percutaneous endoscopic lumbar discectomy. European Spine Journal, 20(1): 58-64.

2. Bakhsh A. (2010): Long-term outcome of lumbar disc surgery: an experience from Pakistan. J Neurosurgery Spine, 12:666-670.

3. Cao, J., Huang, W., Wu, T., Jia, J. and Cheng, X., (2019): Percutaneous endoscopic lumbar discectomy for lumbar disc herniation as day surgery-short-term clinical results of 235 consecutive cases. Medicine, 98(49): e18064

4. Chen, Y., Wang, J. X., Sun, B., Cao, P., Tian, Y., Shen, X. L. and Wu, X. D. (2019): Percutaneous Endoscopic Lumbar Discectomy in Treating Calcified Lumbar Intervertebral Disc Herniation. World neurosurgery, 122: e1449-e1456.

5. Choi I., Ahn, J. O., So, W. S., Lee, S. J. Choi, I. J. and Kim, H. (2013-a): Exiting root injury in transforaminal endoscopic discectomy: preoperative image considerations for safety. European Spine Journal, 22(11), 2481-2487.

6. Choi K. C., Kim JS, Ryu KS, Kang BU, Ahn Y and Lee SH. (2013-b): Percutaneous endoscopic lumbar discectomy for L5-S1 disc herniation: transforaminal versus interlaminar approach. Pain Physician, 16(6):547-556.

7. Choi K. C., Lee, J. H., Kim, J. S., Sabal, L. A., Lee, S., Kim, H. and Lee, S. H. (2015): Unsuccessful percutaneous endoscopic lumbar discectomy: a single-center experience of 10228 cases. Neurosurgery, 76(4): 372-381.
8. Choi Y. S., (2009): Pathophysiology of degenerative disc disease. Asian Spine J, 3:39-44.

9. David G, Ciurea AV, Iencean SM and Mohan A. (2010): Angiogenesis in the degeneration of the lumbar intervertebral disc. J Med Life, 3:154-161.

10. Foley KT and Smith MM. (1997): Microendoscopic discectomy. Techniques in Neurosurg.3: 301-307.

11. Joswig, H., Richter, H., Haile, S. R., Hildebrandt, G. and Fournier, J. Y. (2016): Introducing interlaminar fullendoscopic lumbar diskectomy: a critical analysis of complications, recurrence rates, and outcome in view of two spinal surgeons' learning curves. Journal of Neurological Surgery Part A: Central European Neurosurgery, 77(05): 406-415.

12. Kaushal, M. and Sen, R. (2012): Posterior endoscopic discectomy: Results in 300 patients. Indian journal of orthopaedics, 46(1): 81-85.

13. Lee DY, Shim CS, Ahn Y, Choi YG, Kim HJ and Lee SH. (2009): Comparison of percutaneous endoscopic lumbar discectomy and open lumbar microdiscectomy for recurrent disc herniation. J Korean Neurosurgical Society, 46 (6): 515-521.

14. Lee, C. W., Yoon, K. J., Ha, S. S., and Kang and J. K. (2016): Foraminoplastic superior vertebral notch approach with reamers in percutaneous endoscopic lumbar discectomy: technical note and clinical outcome in limited indications of percutaneous endoscopic lumbar discectomy. Journal of Korean Neurosurgical Society, 59 (2): 172-181.

15. Lehtola, V., Luomajoki, H., Leinonen, V., Gibbons, S. and Airaksinen, O. (2012): Efficacy of movement control exercises versus general exercises on recurrent subacute nonspecific low back pain in a subgroup of patients with movement control dysfunction. Protocol of a randomized controlled trial. BMC musculoskeletal disorders, 13(1): 55-64. 
16. Peng C.W.B., Yeo W. and Tan S. B., (2009): Percutaneous endoscopic lumbar discectomy: clinical and quality of life outcomes with a minimum 2 year follow-up. Journal of Orthopaedic Surgery and Research, 4:20-28.

17. Perez-Curet MJ and Fessler RG (2002): editors. Outpatient spine surgery. 1st ed. St. Louis (MO): Quality Medical Publishing.

18. Ruetten S, Komp M, Mark $H$ and Godolias G. (2009): Recurrent lumbar disc herniation after conventional discectomy. A prospective randomized study comparing full-endoscopic interlaminar and transforaminal versus microsurgical revision. J Spinal Disord Technique, 22; 122-129.

19. Serdar I. S. H. and Sedat C. (2016): Fullendoscopic Interlaminar Lumbar Discectomy Minimally Invasive Spine Surgery. Current Aspects, 12: 69-74.

20. Wang B, Lu G, Patel AA, Ren $P$ and Cheng I. (2011): An evaluation of the learning curve for a complex surgical technique: The full endoscopic interlaminar approach for lumbar disc herniations. Spine J, 11:122-130.

21. Weiler, C., Lopez-Ramos, M., Mayer, H. M., Korge, A., Siepe, C. J., Wuertz, K. and Nerlich, A. G. (2011): Histological analysis of surgical lumbar intervertebral disc tissue provides evidence for an association between disc degeneration and increased body mass index. BMC research notes, 4(1): 497-506.

22. Xia X.-P., Chen H.-L., and Cheng H.-B. (2013): Prevalence of adjacent segment degeneration after spine surgery: a systematic review and meta-analysis. Spine.; 38(7):597608.

23. Xiang H., Xuexiao M., Chen X., and Tongtong G., (2018): Unique complications of percutaneous endoscopic lumbar discectomy and percutaneous endoscopic interlaminar discectomy. Pain physician, 21, E105-E112. 


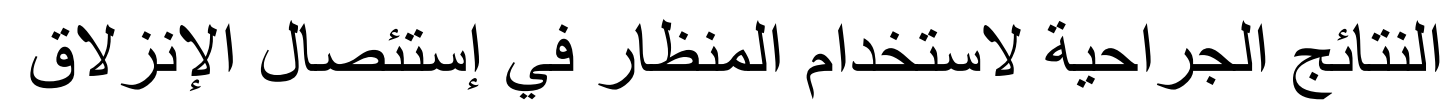

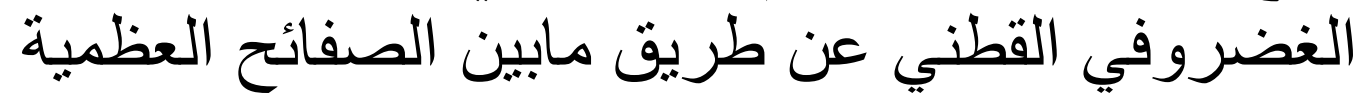
أسامة محمد الغتامث، مأمون محمد أبو شوشةثة، حاتم سعد الخوليث، حسين منتصر

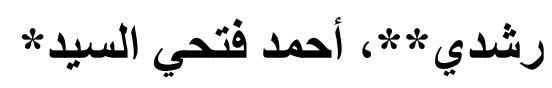

قسمي جراحة المخ والأعصاب* والأشعة**، كلية الطب، جامعة الأزهر

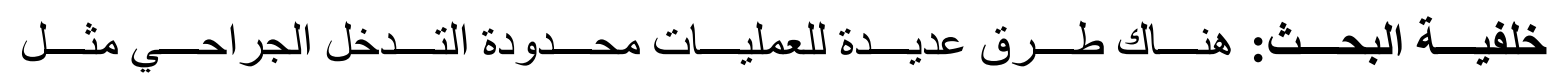

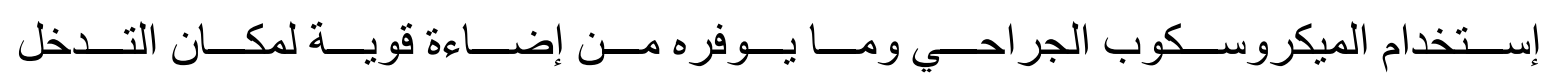

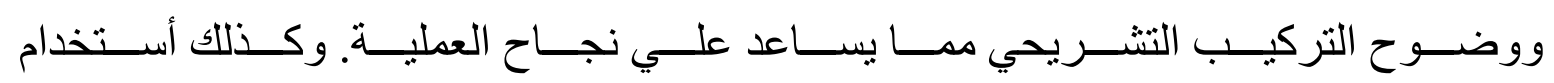

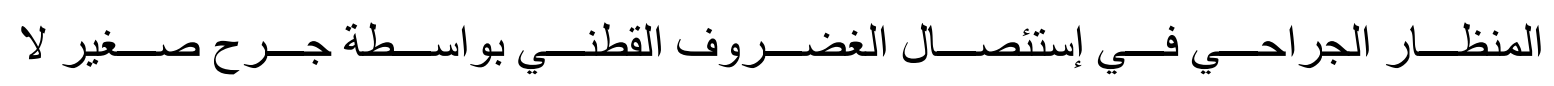

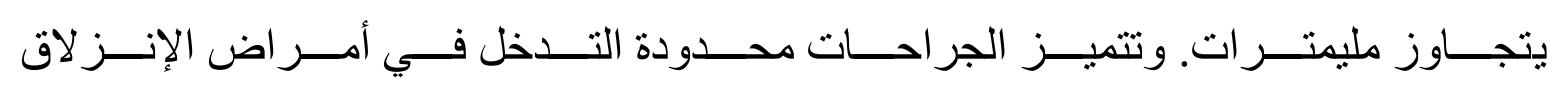

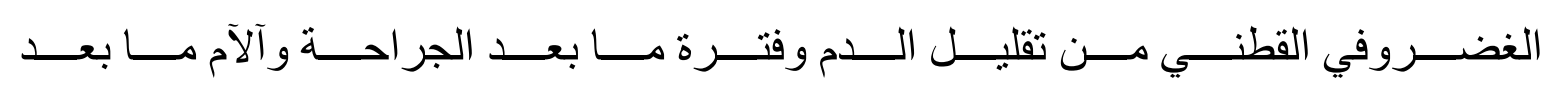
الجر احة ويستطيع العودة للعمل اليومي في وقت قصير.

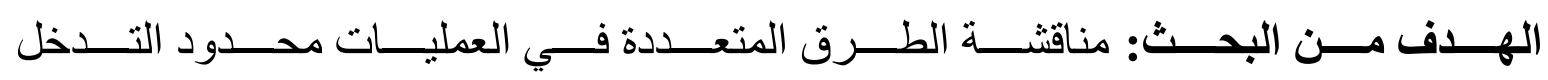

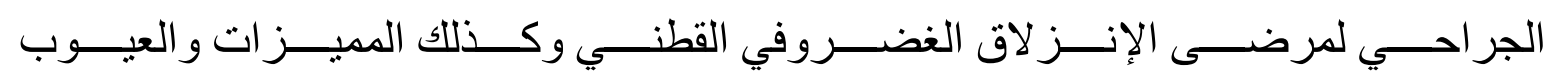

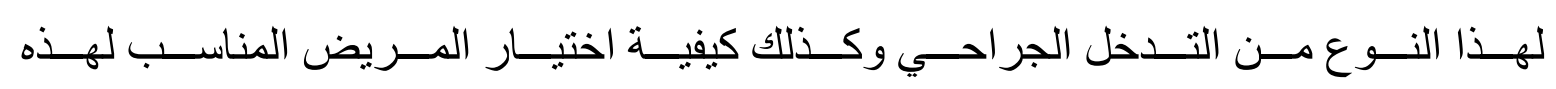
العمليات.

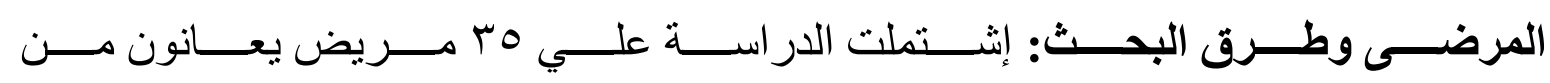

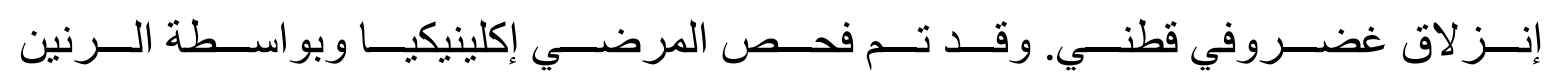

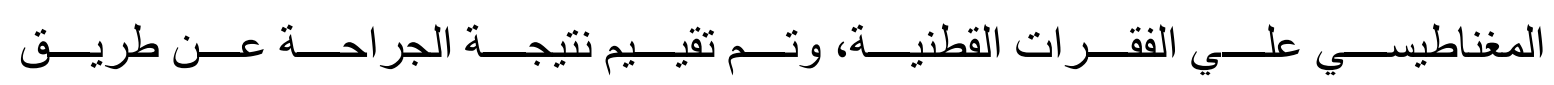
الفحص الإكلينيكي والرنين المغناطيسي.

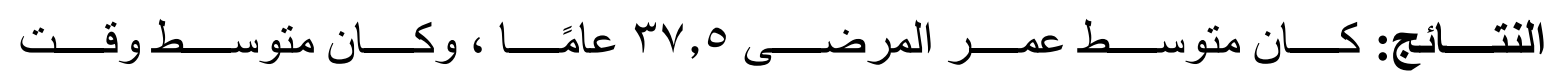

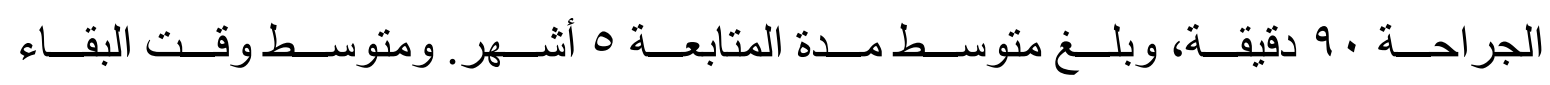

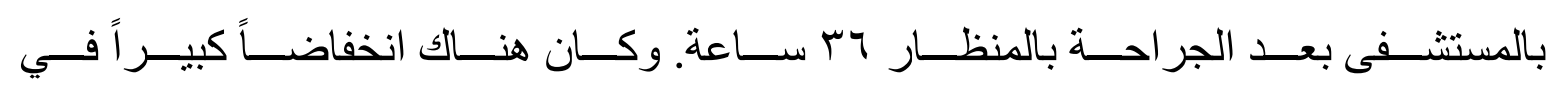

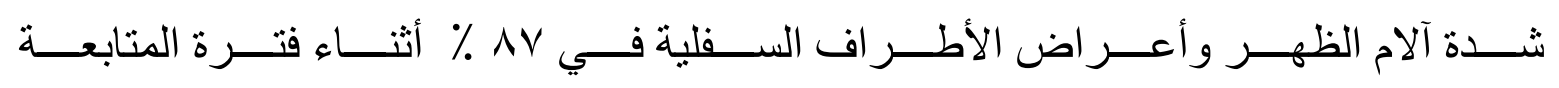




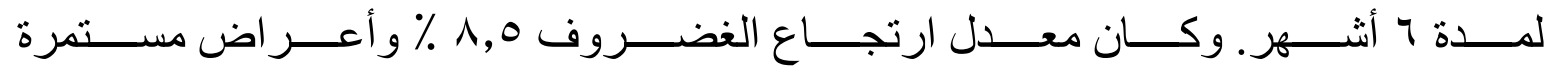

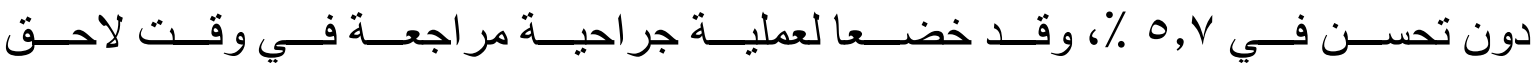

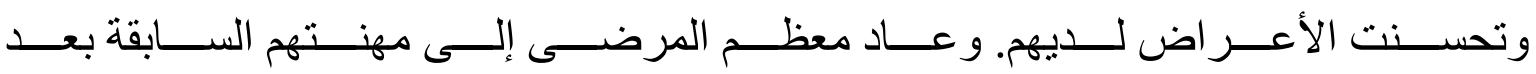
الجراحة في غضون هب يومًا.

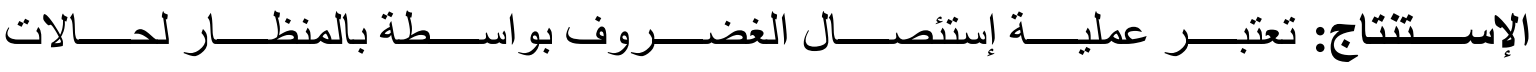

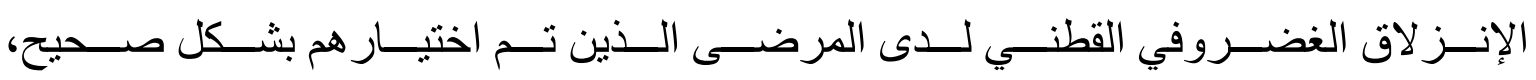
تقنية آمنة ومحدودة التدخل. 